\title{
Pembuatan Sistem Kendali Robot Menggunakan Kamera Berbasis Android
}

\author{
Joni Prayitno ${ }^{1}$, Harso Kurniadi ${ }^{2}$ \\ ${ }^{1}$ Sekolah Tinggi Teknologi Cahaya Surya Kediri \\ ${ }^{2,3}$ Sekolah Tinggi Teknologi Cahaya Surya Kediri \\ 1 aljinromance@gmail.com, ${ }^{2}$ harsok006@gmail.com
}

\begin{abstract}
Abstrak
Seiring berkembangnya dan percepatan teknologi, manusia membutuhkan bantuan dari sesuatu yang dapat bekerja fleksibel, teliti dan tidak mengenal lelah ketika tenaga manusia tidak memungkinkan untuk melakukannya, maka robot adalah jawaban dari permasalahan tersebut. Dalam dunia kemiliteran dan pengamanan sendiri bisa dicontohkan seperti robot pengintai yang dapat digunakan untuk memantau situasi di suatu area yang tidak terjangkau manusia, baik untuk tujuan pengawasan, pemeriksaan keadaan dan sebagainya sehingga manusia hanya perlu mengendalikan robot di suatu tempat dan dapat melakukan perkerjaan tersebut dengan lebih aman. Robot yang dirancang dalam project ini berbentuk robot berkamera tanpa kabel. Dalam project ini dilengkapi dengan modul Wemos dan driver motor L298N untuk mendukung pergerakan robot dan kamera yang digunakan unutk mengirimkan gambar. Semua komponen tersebut terkoneksi oleh smartphone ber-sistem operasi android yang mempunyai aplikasi buatan sendiri untuk menerima gambar dari kamera dan mengendalikan pergerakan robot.
\end{abstract}

Kata kunci- Driver Motor, IP Kamera, Robot, Wemos,.

\section{PENDAHULUAN}

Manusia membutuhkan bantuan dari sesuatu yang dapat bekerja cepat, fleksibel, teliti dan tidak mengenal lelah ketika tenaga manusia tidak memungkinkan untuk melakukannya, maka robot adalah jawaban dari permasalahan tersebut. Robot adalah alat mekanik yang bergerak menggunakan energi listrik dan bisa melakukan tugas fisik berdasarkan program yang telah terinstall. Di antara banyak jenis dan tugas yang dapat dikerjakan suatu robot salah satunya adalah jenis robot beroda yang dilengkapi kamera sehingga dapat melakukan pengawasan jarak jauh yang sedikit berbahaya ataupun melakukan pengawasan yang tidak memungkinkan manusia untuk langsung terjun ke lapangan.

Dalam kasus seperti itu, aplikasi pengembangan dari robot pemantau ini bisa dimanfaatkan petugas penyelamat untuk masuk kedalam lokasi - lokasi yang sulit dijangkau petugas penyelamat pada saat pencarian korban reruntuhan gedung ketika telah terjadi gempa bumi dan juga bisa dimanfaatkan petugas keamanan untuk mengamati keadaan lokasi - lokasi yang akan dilakukan penyergapan atau bisa juga sebagai robot mata - mata [1]. Jika robot tersebut dibuat dengan ukuran yang kecil dan kompleks maka akan memudahkannya untuk melakukan pengintaian.

Berdasarkan latar belakang di atas maka untuk pengajuan Tugas Akhir ini penulis memilih judul "Pembuatan Sistem Kendali Robot Menggunakan Kamera Berbasis Android". Masalah yang akan dibahas pada Laporan Tugas Akhir ini adalah bagaimana 
merancang dan membuat mekanikal robot berkamera dan bagaimana mengintegrasikan sistem wireless sehingga dapat mengakses kamera dan robot tersebut dari jarak jauh melalui media smartphone. Pembuatan dan perancangan sistem yang akan dipakai untuk pengendalian gerak robot adalah Wemos dengan Mikrokontroler ESP8266 sebagai otak robot, L298N sebagai driver motor, IP Cam pada smartphone android sebagai penangkap citra gambar dan smartphone lainnya sebagai pengendali serta penerima transmisi. Tujuan dari dilakukannya penelitian ini adalah untuk mempelajari prinsip kerja sistem komunikasi wireless pada robot berkamera menggunakan modul Wemos berbasis Mikrokontroler ESP8266. Dengan diketahui jarak komunikasi pada robot, diharapkan robot ini dapat mempermudah pekerjaan untuk mengintai pada jarak - jarak tertentu yang lebih bisa dijangkau oleh robot kecil dibandingkan dengan manusia.

\section{WEMOS}

\subsection{Spesifikasi Wemos}

Wemos merupakan salah satu Arduino compatible development board yang dirancang khusus untuk keperluan IoT. Wemos menggunakan chip SoC WiFi yang cukup terkenal saat ini yaitu ESP8266. Cukup banyak modul WiFi yang menggunakan SoC ESP8266. Namun Wemos memiliki beberapa kelebihan tersendiri yang sangat cocok digunakan untuk Aplikasi IoT (Derek, Drs. Elia Kendek Allo, \& Novi M. Tulung, 2016). Beberapa alasan yang membuat Wemos cukup menarik untuk dijadikan main - controller dalam sebuah project adalah sebagai berikut :

A. Arduino compatible, artinya dapat diprogram menggunakan Arduino IDE dengan sintaks program dan library yang hampir sama dengan pemrograman Arduino.

B. Pinout yang compatible dengan Arduino Uno, Wemos D1 merupakan salah satu product yang memiliki bentuk dan pinout standar seperti Arduino Uno. Sehingga memudahkan kita untuk menghubungkan dengan Arduino shield lainnya.

C. Wemos dapat running stand alone tanpa perlu dihubungkan dengan Mikrokontroler. Berbeda dengan modul WiFi lain yang masih membutuhkan Mikrokontroler sebagai pengontrol, Wemos dapat running stand alone karena didalamnya sudah terdapat CPU yang dapat diprogram melalui Serial port ataupun via OTA (Over The Air) atau transfer program secara wireless.

D. High Frequency CPU, dengan processor utama 32 bit berkecepatan $80 \mathrm{MHz}$ Wemos dapat mengeksekusi program lebih cepat dibanding dibandingkan Mikrokontroler 8 bit yang digunakan di Arduino.

E. Dukungan High Level Language, Selain menggunakan Arduino IDE Wemos juga dapat diprogram menggunakan bahasa Python dan Lua. Sehingga memudahkan bagi network programmer yang belum terbiasa menggunakan Arduino. 


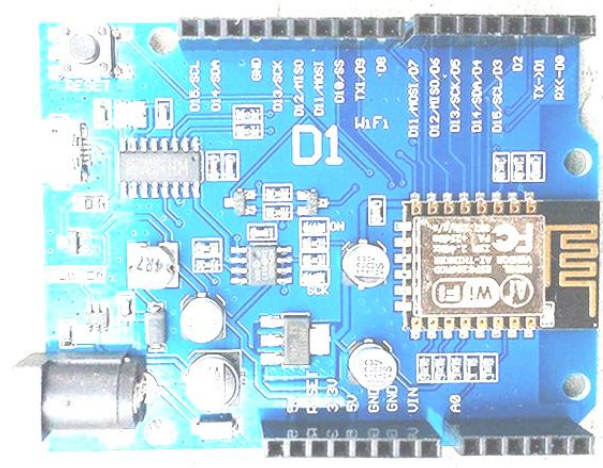

Gambar 1. Modul Wemos D1 berbasis Mikrokontroler ESP8266.

\subsection{Komponen Pendukung}

Android adalah sistem operasi berbasis Linux yang dirancang untuk perangkat bergerak layar sentuh yang juga dipakai sebagai basis dalam smartphone. Android memungkinkan penggunanya untuk memasang aplikasi pihak ketiga ataupun dengan mengunduh dan memasang berkas APK dari situs pihak ketiga. Aplikasi Android dikembangkan dalam bahasa pemrograman Java dengan menggunakan kit pengembangan perangkat lunak Android (SDK). Perkakas pengembangan lain yang tersedia di antaranya adalah Native Development Kit untuk aplikasi atau ekstensi dalam $\mathrm{C}$ atau $\mathrm{C}++$, Google App Inventor, lingkungan visual untuk pemrogram pemula, dan berbagai kerangka kerja aplikasi web seluler lintas platform.

Driver motor L298N merupakan driver motor yang digunakan untuk mengontrol kecepatan dan arah pergerakan motor. Kelebihan dari driver motor L298N ini adalah cukup presisi dalam mengontrol motor. Untuk mengontrol driver L298N ini dibutuhkan 6 buah pin mikrokontroler. Dua buah untuk pin Enable satu buah untuk motor pertama dan satu buah yang lain untuk motor kedua. Karena driver L298N ini dapat mengontrol dua buah motor DC, 4 buah untuk mengatur kecepatan motor motor tersebut. Output dari rangkaian ini sudah berupa dua pin untuk masing masing motor.

Pada prinsipnya rangkaian driver motor L298N ini dapat mengatur tegangan dan arus sehingga kecepatan dan arah motor dapat diatur.Untuk menggerakan motor DC, salah satu cara yang dilakukan adalah dengan menggunakan rangkaian driver L298N. IC L298N adalah IC yang didesain khusus untuk driver motor DC dan dapat dikendalikan dengan rangkaian TTL (Transistor - transistor logic) maupun mikrokontroller. Motor DC yang dikontrol dengan driver IC L298N dapat dihubungkan ke ground maupun ke sumber tegangan positif. Untuk megoperasikan rangkaian Driver Motor IC L298N ini adalah dengan memberikan logika $H I G H$ - LOW dan besaran putaran motor pada teminal input in 1 - in2 dan terminal in3 - in4 [2].

Motor DC adalah sebuah piranti elektronik yang dapat mengubah energi listrik menjadi energi mekanik berupa gerakan berputar atau rotasi. Motor DC yang digunakan pada robot beroda umumnya adalah motor DC dengan magnet permanen. Motor DC jenis ini memiliki dua buah magnet permanen sehingga timbul medan magnet di antara kedua magnet tersebut Di dalam medan magnet inilah jangkar/rotor berputar. Jangkar yang terletak di tengah motor memiliki jumlah kutub yang ganjil dan pada setiap 
kutubnya terdapat lilitan. Lilitan ini terhubung ke area kontak yang disebut komutator. Sikat (brushes) yang terhubung ke kutub positif dan negatif motor memberikan daya ke lilitan sedemikian rupa sehingga kutub yang satu akan ditolak oleh magnet permanen yang berada di dekatnya, sedangkan lilitan lain akan ditarik ke magnet permanen yang lain sehingga menyebabkan jangkar berputar.

\section{HASIL DAN PEMBAHASAN}

\subsection{Arsitektur Sistem}

Penulis melakukan perancangan dan perakitan hardware dengan komponen yang dibutuhkan. Dengan cara penyalaan tiap komponen ketika dipasangkan dalam base robot, dan jika tidak terjadi kendala maka komponen lainnya bisa ditambahkan. Selanjutnya penulis melakukan perancangan pada sistem kontrol robot dengan coding menggunakan Arduino IDE dan dalam sistem android menggunakan MIT App Inventor untuk diimplementasikan ke dalam Mikrokontroler robot. Berikut skema cara kerja dari perancangan mekanikal robot yang akan dikerjakan:

A. Mikrokontroler ESP8266, sebagai otak dari pengendalian robot, di mana program (sketch) dari setiap komponen ditanamkan

B. Baterai, sebagai power yang menyediakan suplai listrik untuk menghidupkan robot.

C. Driver Motor L298, sebagai perantara logika yang dikirim oleh mikrokontroler (otak) untuk diteruskan ke gearbox motor dan kemudian menggerakkan roda.

D. Roda, menggunakan jenis roda rantai (continuous track) yang mendukung pergerakan robot agar lebih leluasa dalam berjalan di medan yang sulit dilewati roda biasa.

E. Smartphone IP Cam, sebagai "mata" utama dari robot dan juga bertugas mengirim gambar yang ditangkap untuk dikirim ke Smartphone controller.

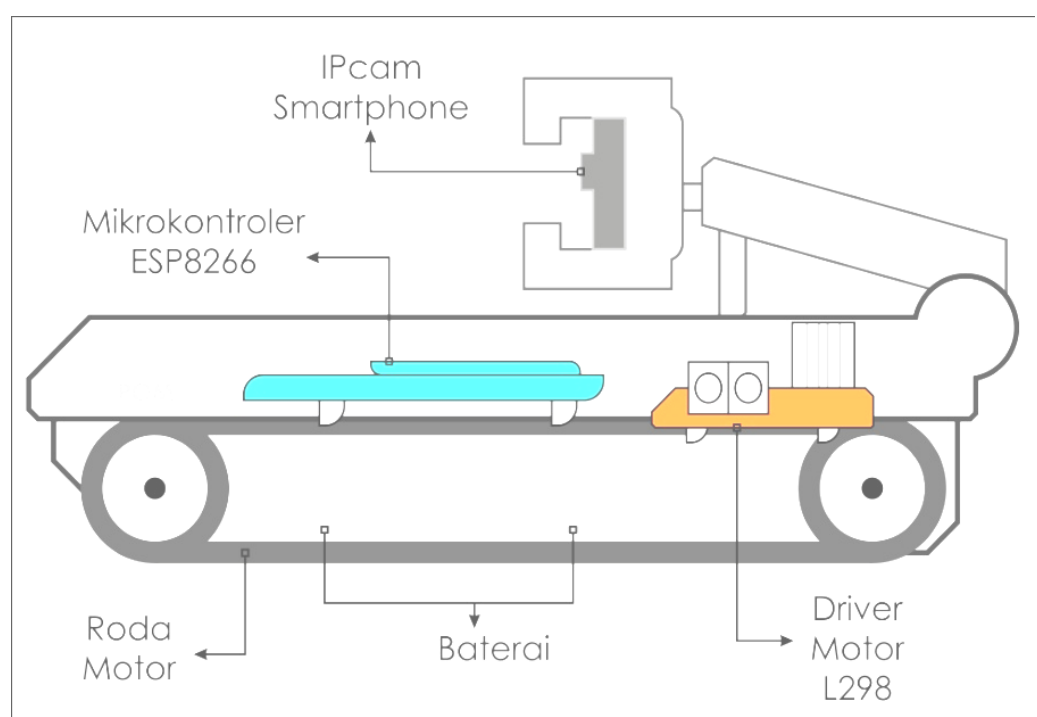

Gambar 2. Perancangan robot tampak samping. 


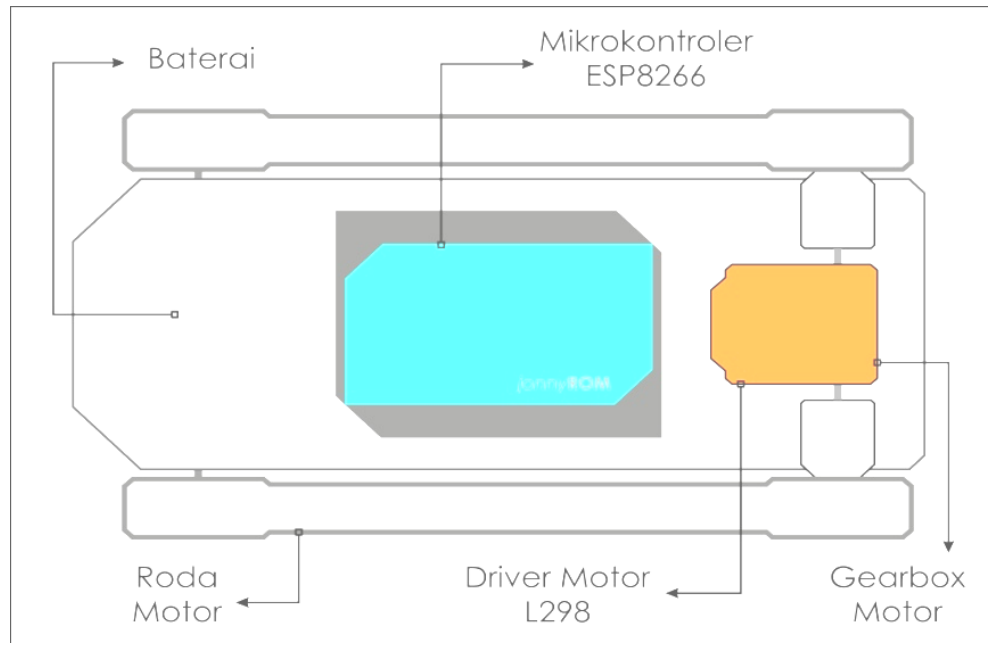

Gambar 3. Perancangan robot tampak atas.

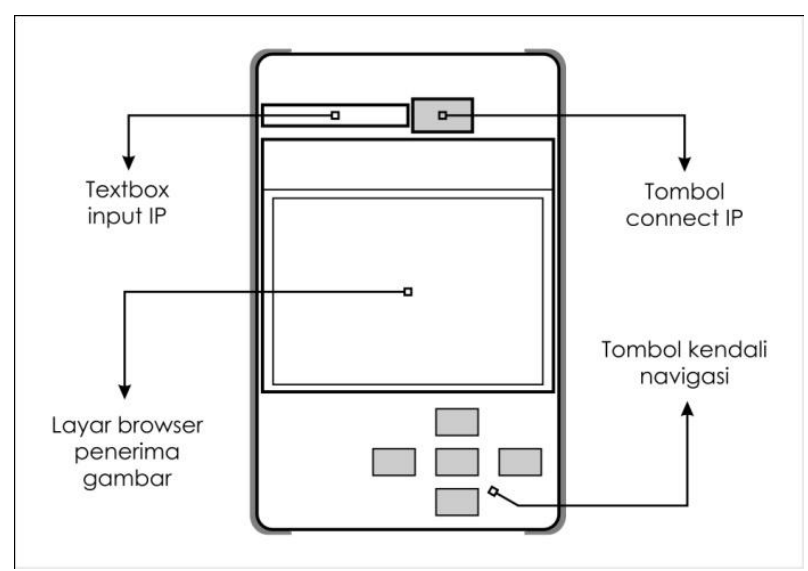

Gambar 4. Perancangan user interface aplikasi di smartphone controller.

\subsection{Diagram Blok}

Robot ini akan menggunakan kamera dari smartphone ber-OS android yang terpasang pada robot dan dikendalikan melalui smartphone lainnya. Keadaan sekitar robot dapat dipantau melalui layar smartphone. Robot dapat bergerak dengan adanya Driver Motor L298N.

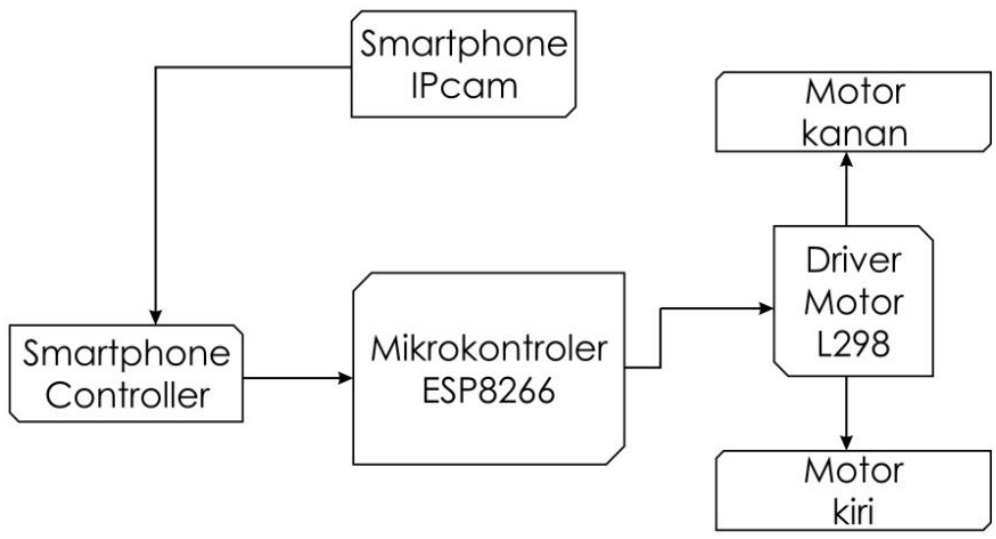

Gambar 5. Diagram blok perancangan sistem robot. 
Penjelasan :

- Robot ini akan menggunakan kamera dari smartphone ber - operating system android yang terpasang pada blok robot dan dikendalikan melalui smartphone lainnya yang terhubung dengan Mikrokontroler.

- Citra dan keadaan sekitar robot akan dapat dipantau melalui layar smartphone.

- Robot dapat bergerak ke kanan, kiri, maju dan mundur dengan adanya Driver Motor L298N, sesuai dengan perintah yang dikirim melalui button yang dirancang dalam smartphone.

- Agar dapat dikendalikan dalam jarak yang jauh maka menggunakan jaringan wireless melalui driver Wemos yang terdapat pada blok robot.

- Mikrokontroler yang digunakan adalah Mikrokontroler ESP8266 dengan menggunakan bahasa $\mathrm{C}$, dan juga menggunakan catu daya 9 Volt untuk mengaktifkan sistem Mikrokontroler dan juga mengaktifkan kamera.

\subsection{Alat dan Bahan Penelitian}

Beberapa alat dan bahan yang digunakan dalam perancangan robot berkamera ini dapat dilihat dalam tabel berikut:

Tabel 1. Alat dan bahan yang dibutuhkan.

\begin{tabular}{|l|l|}
\hline \multicolumn{1}{|c|}{ Alat } & \multicolumn{1}{c|}{ Bahan } \\
\hline A. Laptop & A. Wemos D1 (Mikrokontroler ESP8266) \\
B. Software Arduino I. D. E & B. Smartphone android (Sistem Operasi Android) \\
C. Kabel USB & C. Driver Motor L298N \\
D. Obeng & D. Motor DC \\
E. Tang & E. Smartphone android (sebagai IP Cam) \\
F. Solder & F. Roda \\
G. Bor Listrik & G. Chassis \\
H. Lem bakar & H. Kabel jumper \\
I. Gunting & I. Spacer \\
J. Double-tape & \\
\hline
\end{tabular}

\subsection{Flowchart Diagram}

Menurut [3], menjelaskan bahwa "Bagan alir (flowchart diagram) dokumen merupakan bagan alir yang menunjukan arus dari laporan dan formulir termasuk tembusan - tembusannya. Bagan alir dokumen ini menggunakan simbol - simbol yang sama dengan yang digunakan di dalam bagan alir sistem”. Berikut flowchart diagram rancangan sistem robot ini yang terbagi menjadi 2 prosedur, yaitu prosedur $\mathrm{A}$ dan prosedur B, yang dibuat berdasarkan pengertian bagan alir di atas. Untuk prosedur A, dijelaskan oleh flowchart ketika program dijalankan, maka program akan parsing IP dengan smartphone IP Cam, jika IP address yang dimasukkan benar dan koneksi terhubung maka smartphone IP Cam akan menangkap gambar dan mengirimnya ke layar smartphone controller. 


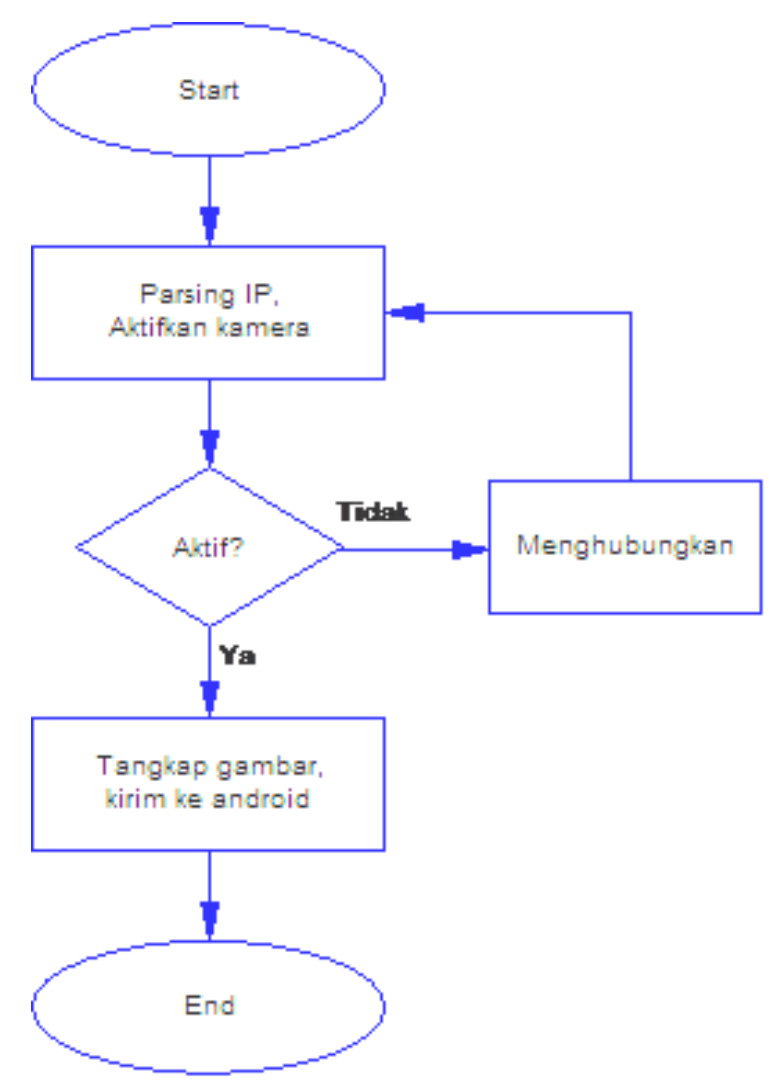

Gambar 8. Flowchart diagram blok "A” rancangan sistem robot.

Pada prosedur yang kedua, yaitu prosedur B. Dalam program ini ketika aplikasi dijalankan, maka program akan membuka koneksi dari smartphone controller ke driver Wemos pada robot. Cara kerja dari parsing dua perangkat ini adalah, pada smartphone controller sudah dimasukkan kode yang akan disesuaikan dengan program yang terdapat pada mikrokontroler [4]. Contohnya kode "f-" pada program smartphone controller ketika dikirim ke driver Wemos pada robot maka akan diterima sebagai perintah ke driver motor untuk bergerak maju dalam program mikrokontroler, dan begitu seterusnya untuk kode - kode yang lain.

\subsection{Instalasi Software}

Pertama kali sebelum memulai project, yang harus disiapkan adalah software program yang digunakan untuk melakukan coding sistem pada robot yaitu software Arduino IDE dan mendownload library esp8266 Built - In untuk memastikan jika software Arduino memiliki library dan bisa compatible dengan modul Wemos yang digunakan dalam project ini. Untuk aplikasi pada android, penulis mengunakan AppInventor, yaitu situs online yang berisi tools dan dapat digunakan untuk membuat aplikasi android. AppInventor berbasis visual block programming, yaitu programming yang dilakukan dengan cara melihat, menggunakan, menyusun dan drag - drops "blok" yang merupakan simbol - simbol perintah dan fungsi tertentu dalam membuat aplikasi. Atau dalam bahasa lain, secara sederhana ini adalah cara membuat program tanpa menuliskan kode program [5], Berikut contoh tampilan perancangan User Interface dan blok programming dalam App Inventor : 


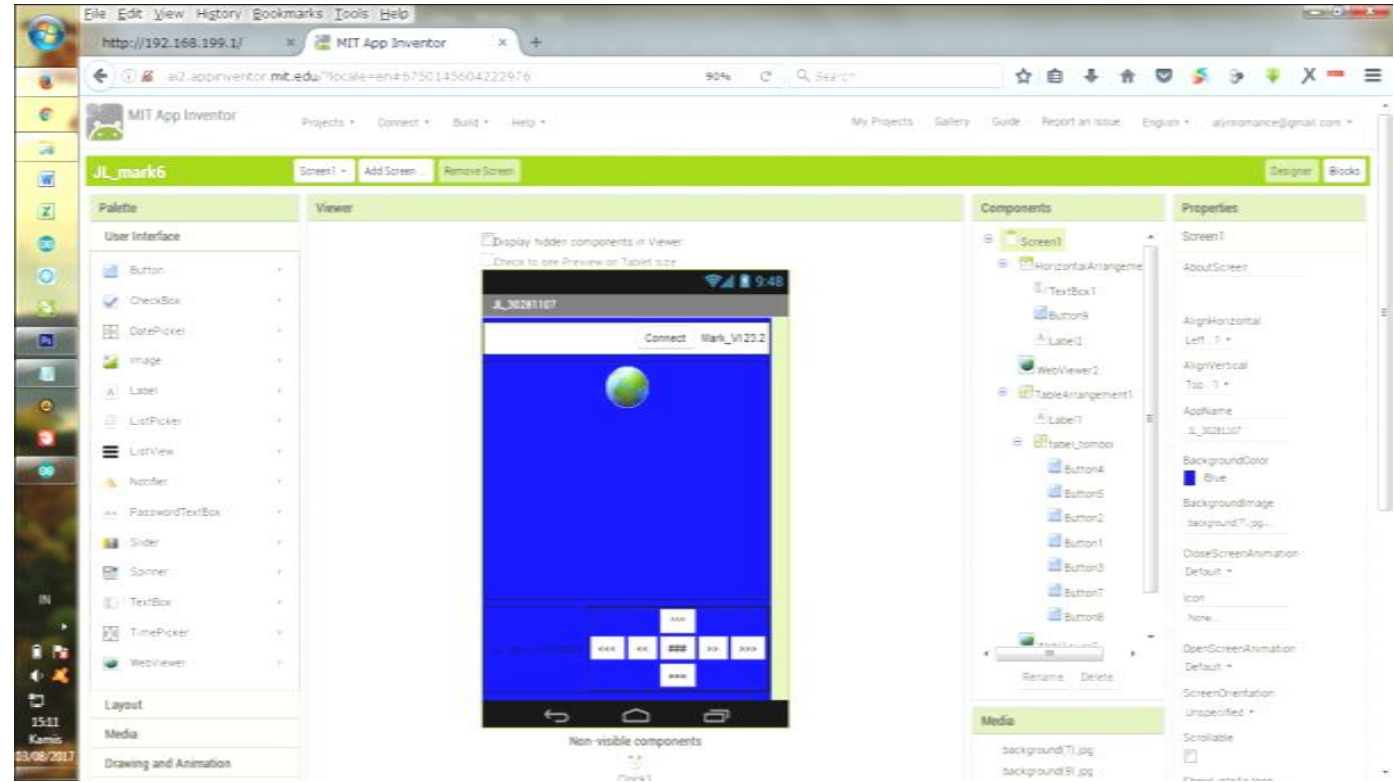

Gambar 10. Perancangan User Interface dalam App Inventor.

\subsection{Instalasi Hardware}

Perancangan instalasi hardware dilakukan dengan menghubungkan setiap komponen yang dibutuhkan menggunakan kabel jumper. Dalam perancangan instalasi hardware di bawah ini digunakan sebuah modul Wemos, sebagai komponen utama yang mengatur logika driver motor L298 untuk menggerakkan motor DC. Catu daya pada sistem dan driver motor menggunakan baterai jenis Alkaline dengan power 9 Volt untuk sistem dan jenis AA dengan power 6 Volt untuk driver motor. Normalnya, modul Wemos dapat menerima power antara 5-12 Volt sedangkan driver motor dapat menggerakkan motor DC dengan tenaga 3-12 Volt. Rancangan instalasi hardware dalam rangkaian fritzing terlihat seperti gambar di bawah ini.

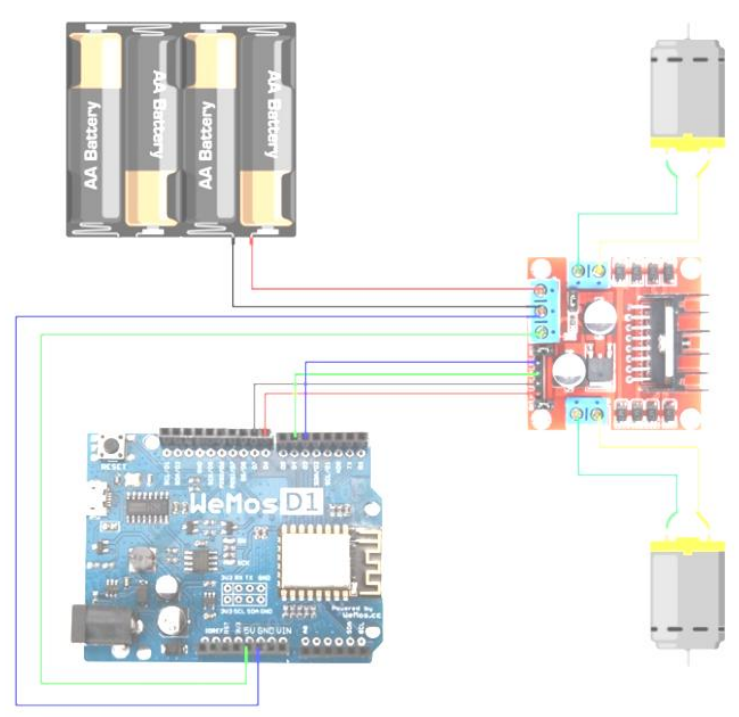

Gambar 11. Perancangan rangkaian instalasi hardware utama robot keseluruhan. 


\subsection{Estimasi Biaya}

Adapun perkiraan biaya komponen, kebutuhan pendamping dan pembuatan keseluruhan robot ini adalah sebagai berikut :

Tabel 2. Estimasi Biaya.

\begin{tabular}{|l|l|ll|ll|}
\hline Komponen & Jumlah & \multicolumn{2}{|l|}{ Biaya } & \multicolumn{2}{l|}{ Total } \\
\hline \hline Wemos D1 & 1 & $\mathrm{Rp}$ & 100.000 & $\mathrm{Rp}$ & 100.000 \\
\hline Chassis robot & 1 & $\mathrm{Rp}$ & 300.000 & $\mathrm{Rp}$ & 300.000 \\
\hline Holder & 1 & $\mathrm{Rp}$ & 20.000 & $\mathrm{Rp}$ & 20.000 \\
\hline Battery clip & 1 & $\mathrm{Rp}$ & 2.000 & $\mathrm{Rp}$ & 2.000 \\
\hline $\begin{array}{c}\text { Driver } \\
\text { L298NN }\end{array}$ & 1 & $\mathrm{Rp}$ & 45.000 & $\mathrm{Rp}$ & 45.000 \\
\hline $\begin{array}{l}\text { IP Cam } \\
\text { smartphone }\end{array}$ & 1 & $\mathrm{Rp}$ & 300.000 & $\mathrm{Rp}$ & 300.000 \\
\hline & \multicolumn{3}{|c|}{ Total Biaya } \\
\hline
\end{tabular}

\section{KESIMPULAN}

Berdasarkan langkah demi langkah perancangan, perakitan, implementasi sistem hingga semua hasil pengujian di atas, berikut beberapa hal yang dapat disimpulkan, robot dapat bergerak ke segala arah; maju, mundur, kanan, kiri dan berhenti dan smartphone IP Cam dapat mengirim gambar ke smartphone controller. Tombol pada smartphone pengendali tidak berfungsi, error seperti ini juga terjadi pada gambar yang dikirim oleh IP Cam yang kadang tersendat, hal ini bukanlah kesalahan program melainkan koneksi pada jaringan internet yang tidak lancar atau putus - putus.

Mengganti smartphone IP Cam dengan IP Cam murni sepertinya akan membuat robot lebih baik, dengan begitu robot akan dapat "melihat" dalam keadaan yang lebih variatif seperti dalam keadaan gelap. Jaringan internet dalam kondisi yang stabil. membuat kontrol robot bisa lancar tanpa ada delay. Power supply dengan spesifikasi yang tertera pada sub-bab Instalasi Hardware dibab sebelumnya hanya mampu bertahan selama 15-20 menit pemakaian non-stop. Diharapkan untuk pengembangan dapat menggunakan jenis baterai yang lebih baik sehingga jangkauan jelajah lebih luas dan lebih lama.

\section{DAFTAR PUSTAKA}

[1] Saleh, K., 2013, Rancang Bangun Robot Pemantau Wireless Berbasis Mikrokontroler ATMega8535 Menggunakan Bahasa Basic, Jurnal Penelitian Sains, 15.

[2] Pribadi, I. P., 2012, Robot Pengintai Menggunakan PC Berbasis Mikrokontroler AT89S51, Skripsi Sistem Komputer, Ilmu Komputer dan Teknologi Informasi Universitas Gunadarma, 2.

[3] Hartono, J., 2005, Analisis dan Desain Sistem Informasi, Yogyakarta: Andi Offset.

[4] Amrillah, A., H, 2015, Sistem Kendali Robot Pengintai Menggunakan Kontrol Komputer Berbasis Mikrokontroler Arduino, Jurnal Informatika Global, Volume 6 No.1, 22. 
[5] Fatekha, R. A., (2013, Februari 19), Ganesha RoboSoccer. Retrieved Juli 08, 2017, from Parsing Data Di Arduino: https://grsbatch5.wordpress.com/2013/02/19/parsing-data-di-Arduino/ 